\section{DNA-basierte Immuntherapie gegen Krebs}

\author{
M. Schroff ${ }^{1}$ \\ ${ }^{1}$ CEO, MOLOGEN AG, Berlin
}

Die immunmodulierende Wirkung bakterieller DNA war seit vielen Jahrzehnten [1] bekannt, als das Sequenzmotiv mit der Basenfolge Cytosin-Guanin, wenn Cytosin wie für prokaryontische DNA typisch nicht methyliert ist, Mitte der 1990er-Jahre als das aktive Agens identifiziert wurde [2]. Daraufhin setzten vielfältige präklinische und klinische Entwicklungen ein, um das immunmodulatorische Agens als Adjuvans für Impfstoffe zur Infektionsbekämpfung und insbesondere zur Therapie bei Krebserkrankungen einzusetzen [3].

Das Design der bei den Entwicklungen zum Einsatz kommenden DNA-Moleküle wurde bestimmt durch die damaligen technischen und wissenschaftlichen Limitationen. Die Synthese längerer DNA > 50-Nukleotide $(\mathrm{N})$ und großer Mengen dieser DNA, insbesondere unter GMP-Bedingungen, war nicht etabliert. Die Aufnahme in Zellen von kurzen DNA-Molekülen, sogenannter Oligodesoxyribonukleotide (ODN) $<30$ $(\mathrm{N})$, schien effektiver zu sein als die längere und doppelsträngige DNA. Auch die Molekularbiologie, Signaltransduktion, zelluläre Verteilung und Speziesspezifität des zugehörigen Rezeptors, TLR-9, waren zu diesem Zeitpunkt noch nicht bekannt. In der Konsequenz konzentrierte man sich auf die präklinische Entwicklung einzelsträngiger ODN mit einer Länge von weniger als 30 Nukleotiden. Bedingt durch die geringe Länge und die offenen Enden der einzelsträngigen ODN hatten diese nur eine sehr kurze Halbwertszeit im Säugerorganismus und konnten so ihre immunmodulatorische Wirkung nicht erzielen. Um sie vor dem extra- und intrazellulären Abbau zu schützen, kamen deshalb chemische Schutzgruppen und in Säugerorganismen nicht vorkommende Nukleotidverknüpfungen zum Einsatz, von denen die Modifikation mit Phosphothioaten (PTO) am häufigsten verwendet wurde.

In präklinischen und klinischen Tests der vergangenen 10 Jahre wurde dann jedoch festgestellt, dass die PTO-Modifikation und andere nicht biologische Bindungen in den ODN sowohl toxisch sind als auch eigene immunmodulatorische Wirkungen haben. Die Summe dieser und weiterer Effekte führte für die ODN in der klinischen Entwicklung zu einem schmalen therapeutischen Fenster, das zumindest in den monotherapeutischen klinischen Studien zur Therapie gegen Krebs keine ausreichend hohe und langdauernde Dosierung zuließ. Weiterhin konnte die zu Beginn der Entwicklung von therapeutischen ODN vorhandene Limitierung auf sehr kurze Moleküle durch Verbesserungen der Synthesetechnik überwunden werden. Dadurch ergaben sich völlig neue Möglichkeiten zur Entwicklung von DNA-basierten Therapeutika.

Basierend auf der Grundlagenforschung von Professor Wittig (Institut für Molekularbiologie und Biochemie, Freie Universität Berlin) zu Struktur und Funktion kovalent geschlossener DNA-Moleküle und mit seiner Unterstützung hat die MOLOGEN AG ein „hantelförmiges“, kovalent geschlossenes DNAMolekül mit einer Länge von 116 Basen entwickelt, das einen doppelsträngigen (stem) und 2 einzelsträngige (loop) Anteile aufweist. Dieser „double stem-loop immunomodulator“ $\left(\mathrm{dSLIM}^{\circledR}\right)$ enthält in den beiden Loops nichtmethylierte CGMotive, die vom TLR-9-Rezeptor erkannt werden. dSLIM ${ }^{\circledR}$ ist aufgrund seiner Struktur, die keine offenen Enden aufweist, vor dem schnellen Abbau durch Exonukleasen geschützt und kann somit vollständig auf chemische Modifikationen verzichten. Durch die völlig andersgeartete Struktur von dSLIM ${ }^{\circledR}$ im Vergleich zu PTO-modifizierten, linearen ODN ergeben sich deutliche Unterschiede im Aktivierungs- und Sicherheitsprofil. Diese werden exemplarisch an experimentellen und präklinischen Daten dargestellt. dSLIM ${ }^{\circledR}$ befindet sich zurzeit in fortgeschrittener klinischer Entwicklung und hat sich bisher als sicherer und sehr gut verträglicher DNA-basierter Immunmodulator in der Monotherapie gegen Darmkrebs erwiesen.

Interessenkonflikt: Der Autor ist Mitarbeiter der MOLOGEN AG.

\section{Literatur}

1 Tokunaga T, Yamamoto H, Shimada S, Abe H, Fukuda T, Fujisawa Y, Furutani $Y$, Yano $O$ et al. Antitumor activity of deoxyribonucleic acid fraction from Mycobacterium bovis BCG. I. Isolation, physicochemical characterization, and antitumor activity. J Natl Cancer Inst 1984; 72 (4): 955-962

2 Krieg AM, Yi AK, Matson S, Waldschmidt TJ, Bishop GA, Teasdale R, Koretzky GA, Klinman DM. CpG motifs in bacterial DNA trigger direct B-cell activation. Nature 1995; 374 (6522): 546-549

3 Vollmer J, Krieg AM. Immunotherapeutic applications of $\mathrm{CpG}$ oligodeoxynucleotide TLR9 agonists. Adv Drug Deliv Rev 2009; 61 (3): 195-204

\section{Bibliografie}

Dol http://dx.doi.org/10.1055/s-0032-1324905

Arzneimittelforschung 2012; 62, Suppl. 1: S11-S11

(c) Georg Thieme Verlag KG Stuttgart · New York .

ISSN 0004-4172 